Article

\title{
An Efficient Ensemble VTOPES Multi-Criteria Decision-Making Model for Sustainable Sugarcane Farms
}

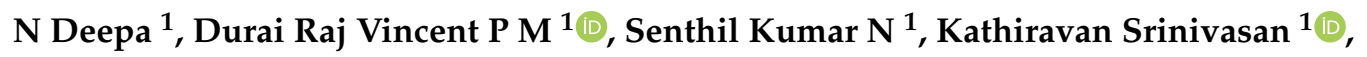 \\ Chuan-Yu Chang ${ }^{2, *(1)}$ and Ali Kashif Bashir ${ }^{3}$ (i) \\ 1 School of Information Technology and Engineering, Vellore Institute of Technology, Vellore 632 014, \\ Tamil Nadu, India \\ 2 Department of Computer Science and Information Engineering, National Yunlin University of Science and \\ Technology, Yunlin 64002, Taiwan \\ 3 Department of Computing and Mathematics, Manchester Metropolitan University, Manchester M15 6BH, UK \\ * Correspondence: chuanyu@yuntech.edu.tw
}

Received: 29 June 2019; Accepted: 5 August 2019; Published: 8 August 2019

check for updates

\begin{abstract}
The role of Information Technology based decision models for sustainable agriculture has gained immense prominence in recent years. Ranking of agriculture farms based on their yield plays a vital role in sustainable agriculture. In this work, an ensemble decision-making model, namely VIKOR (Vlsekriterijumska Optimizacija I Kompromisno Resenje), TOPSIS (Technique for Order Preference by Similarity to an Ideal Solution), entropy, and standard deviation (VTOPES), is proposed for ranking the sustainable sugarcane farms. VTOPES system model comprises of four significant steps: (i) determination of significance scores of the sub-parameters, (ii) transformation of sub-parameter sequences into main parameter values, (iii) computation of significant scores of main parameters, and (iv) generation of assessment values and deploying it for ranking the sugarcane farms. The ranking results of the proposed VTOPES model are compared with the ranking patterns obtained from five years average yield data acquired from the selected sugarcane farms. Moreover, the outcomes of the VTOPES model are also compared with other prevalent methods. Subsequently, Spearman's rank correlation method is applied for evaluating the impact of correlation of VTOPES ranks in comparison with the average yield ranks. Thus, it can be noticed that the empirical results of the VTOPES model provide reliable and sustainable results. Therefore, it suffices to be a sustainable decision model for any problem where multiple parameters are involved.
\end{abstract}

Keywords: VIKOR; decision model; TOPSIS; entropy; sustainable agriculture

\section{Introduction}

India is an agronomy-based nation, and more than $50 \%$ of the country's employment is accomplished through agriculture [1]. According to the worldometers report [2], in 2019, the Indian population is reported to be 1.37 billion, and it is increasing at a prominent pace. Further, this, in turn, will demand the farmers to generate a higher amount of cultivable produce. Also, the primary point to be noted here is that only 60 percent of the land is suitable for doing cultivation. Based on the prediction by the econometric models [3] the gross domestic product (GDP) of India's agriculture by 2020 is expected to reach approximately INR 7000 Billion. It is clearly evident from these figures that India's significant chunk of GDP is dependent on agriculture.

Furthermore, farmers in India come across numerous problems and issues such as frequently varying weather, typhoons, floods, tsunami, landslides, earthquakes, and poor quality of the soil. Therefore, to overcome such challenges, in addition to traditional knowledge, the farmers might 
require support from various emerging technologies and decision systems. Moreover, the failure of agriculture might also influence the production of allied businesses, and all these factors put together will have a strong influence on the nation's GDP and growth. Also, it is essential to keep the inflation in check by continually monitoring and supporting the different contributing areas of the nation's GDP. It is a fact that in third world nations' such as India, the agriculturists lack quality education and cognizance about the modern-day technological advancements and practices in farming. Further, it becomes essential for the agriculturists to make several decisions such as choosing the type of crop, based on numerous factors like seasons, rainfall, soil quality and condition, and so on. Hence, technology-supported decision-making becomes a significant part of the farming process. Several decision-making models have been developed so far in the field of agriculture [4-8].

The sharp increase in population is much more severe in some countries around the world, particularly in India. There is a demand for food being increased every year along with the increase in population. Further, this can be solved by applying sustainable agriculture practices. The selection of land for crop cultivation has a significant impact on sustainable agriculture. An essential requirement for long term productivity and profitability obtained from farming in rural areas is sustainable agriculture development. Sustainable agriculture includes social, financial, and environmental aspects. Crop productivity is one of the essential elements in the financial aspects of farming [9]. Identification of suitable farm for crop cultivation is essential to maximize the productivity of crops. Crop production relies on multiple criteria that may differ from place to place. The present work emphasis on the sugarcane farm selection that considers comprehensive parameters for sustainable farming.

Several decision models have been developed so far for the development of sustainable agriculture. A decision support model was developed for the selection of cropping pattern using Fuzzy and multi-criteria decision making (MCDM) approaches for sustainable agriculture development [9]. A stochastic decision model was developed using multi-criteria decision analysis to select sustainable biomass crop for the production of biofuels with multiple conflicting criteria [10]. A decision model was proposed to rank sustainable energy conversion technologies, which convert agriculture residues to energy using Fuzzy analytic network process (ANP) and VIKOR (Vlsekriterijumska Optimizacija I Kompromisno Resenje) methods [11]. A model was developed to identify the best water supply management alternative for sustainable agriculture using VIKOR, and Fuzzy Order weighted average methods for climate-change adaptation [12]. A hybrid model was developed to select sustainable supply chain for Agri produce in India using Interpretive Structural Modeling (ISM), decision making trial and evaluation laboratory (DEMATEL), analytic network process (ANP) methods [13].

Multi-criteria decision making (MCDM) approaches are used to develop useful decision-making tools when multiple conflicting criterions are taken into consideration for a given problem. In the existing literature, several MCDM methods have been used for ranking and predicting the best solution among the specified alternatives. A Technique for Order Preference by Similarity to an Ideal Solution (TOPSIS) is a renowned MCDM technique with the capability of choosing the best alternative in close proximity with the positive ideal solution and at the same time far away from the negative ideal solution [14,15]. The Vlsekriterijumska Optimizacija I Kompromisno Resenje (VIKOR) is a popular and pragmatic MCDM technique, which can be employed for resolving decision problems in business management, sustainable agriculture, supply chain networks, production and design, and so on [16,17]. Further, the grey relational analysis (GRA) is a well-known MCDM technique that amalgamates together the quantitative and qualitative information which assumes either the largest or smallest evaluation criteria value $[18,19]$. A simple additive weighting $(S A W)$ is a straightforward technique in which the preference measures are determined for every alternative using the sum of products of weights and alternative values [20,21].

Several decision models have been developed by integrating MCDM methods. A decision model was developed using 11 parameters to predict green supplier in the supply chain using VIKOR and TOPSIS [22]. VIKOR and TOPSIS methods have been used to develop a ranking model to rank and monitor the countries based on their performance [23]. An integrated MCDM model was 
developed using AHP [24] and VIKOR for the selection of Hazardous Waste Carrier to provide a clean environment and to reduce the transportation cost [25]. A group decision-making method was developed by integrating ELimination and Choice Expressing REality(ELECTRE) [26] and VIKOR method for solving outranking problems with uncertainty [27]. AHP and TOPSIS have been integrated with Fuzzy in order to assess the Human Resource in Asian countries [28]. In this VTOPES (VIKOR, TOPSIS, entropy, standard deviation) model, VIKOR and TOPSIS approaches are integrated for decision making.

In general, feature selection is essential in decision making, where classification and predictions are involved [29]. In MCDM, weight computation plays a vital role in the decision-making process. When multiple parameters are involved in decision making, it cannot be concluded that each parameter has the same meaning and importance. Therefore, it is mandatory to compute the weights of parameters in the decision-making process. In practice, there are numerous approaches for determining the weights of various parameters. In general, the determination of the weights can be classified into two major types, the first is said to be the subjective approach, and the second one is termed as the objective approach. The computation of the weights in the first approach is based on specialists' advice, substantiation, and validation. Whereas, in the second approach, the computation of weights is accomplished with the support of mathematical models.

Shannon's entropy approach is an objective weight calculation approach usually deployed to handle uncertain problems [30]. The correlation coefficient and standard deviation (CCSD) technique is a weight computation approach in which the criterions' objective weights are calculated [31]. Standard deviation (SD) is another simple objective weight calculation method which considers mean and standard deviation of parameters for weight assignment. Analytical hierarchy process (AHP) is one of the MCDM approaches and is also used for subjective weight calculation of parameters [32]. Weighted least square method is another popular subjective method used for weight calculation of parameters [33]. Another subjective assignment method which assigns weight by considering the experts' opinion is the Delphi method [34,35]. In this work, Shannon's entropy method and SD method are used for the weight assignment of parameters.

The key contributions of this work are summarized as follows:

(i) This proposed VTOPES model is a general approach that aims to predict the best alternative in decision-making problems effectively and can be further applied to other decision problems.

(ii) In this work, the significant scores of each parameter are evaluated based on the proportional weights for better decision making.

(iii) Even though sub-parameters have a strong influence on the decision-making process, they are seldom considered in many of the previous research works. Hence, it is necessary to have a hybrid model that will consider both the main parameter and sub-parameters in order to select the best sustainable sugarcane farms.

(iv) As of now, there is no generic multi-criteria decision-making model for solving decision problems characterized by multiple conflicting criteria.

(v) The proposed work offers superior performance in terms of ranking results when compared with the other existing MCDM methods.

The organization of the paper is as follows: In the next section, the steps involved in the development of VTOPES model is explained. In Section 3, the results of VTOPES model has been discussed and further validated with other MCDM methods.

\section{Proposed VTOPES Model}

The VTOPES decision model is proposed to predict the best alternative from the given set of alternatives which are characterized by multiple parameters. The VTOPES model considers the significance score of the parameters with respect to the alternatives and takes the appropriate decision. Entropy and standard deviation methods have been applied to find the significance scores of the 
parameters. VIKOR and TOPSIS methods are applied to generate final assessment values of alternatives which are used to rank the given set of alternatives. The list of symbols and notations used in the VTOPES model is depicted in Table 1.

Table 1. List of symbols and their definitions used in the VTOPES (VIKOR, TOPSIS, entropy, and standard deviation) model.

\begin{tabular}{cc}
\hline Symbol & Definition \\
\hline$Y_{i j}$ & Main parameter matrix \\
$\eta_{j}$ & Entropy \\
$\eta_{\boldsymbol{o}}$ & Entropy Constant \\
$m$ & Number of alternatives \\
$n$ & Number of sub-parameters under each main parameter \\
$\boldsymbol{D}_{j}$ & Degree of Divergence of $j^{t h}$ sub-parameter \\
$u_{j}$ & Weight of $\boldsymbol{j}^{\text {th }}$ sub-parameter \\
$\boldsymbol{A}$ & Measure of Utility \\
$\boldsymbol{B}$ & Measure of Regret \\
$\boldsymbol{K}_{t}$ & Ranking indices of alternatives' main parameters \\
$\boldsymbol{P}$ & Ranking indices of Matrix \\
$\boldsymbol{S}$ & Standard Deviation \\
$\boldsymbol{V}$ & Main parameter weights \\
$\boldsymbol{E}$ & Weighted Normalized Matrix \\
$\boldsymbol{H}^{+}$ & Positive Ideal Solution \\
$\boldsymbol{H}^{-}$ & Negative Ideal Solution \\
$\boldsymbol{C}_{t}$ & Partitioned Column Matrix \\
$\boldsymbol{Z}_{i}^{+}$ & Separation distance of each alternative from the positive ideal solution \\
$Z_{i}^{-}$ & Separation distance of each alternative from the negative ideal solution \\
$\Lambda$ & Relative proximity with a positive ideal solution \\
\hline
\end{tabular}

The raw data obtained for decision making consists of $m$ alternatives and multiple parameters. Multiple parameters identified for the decision-making problem are grouped into $g$ main parameters, and each main parameter has its own sub-parameters. Each main parameter matrix $Y$ consists of $m$ alternatives and $n$ sub-parameters.

The proposed VTOPES model is described as follows:

\section{VTOPES model}

For $g$ main parameters matrix $Y$ with $m$ alternatives and $n$ sub-parameters do the following:

\section{Determination of Entropy}

$$
S_{j}=-S_{o} \sum_{i=1}^{m} Y_{i j} \ln \left(Y_{i j}\right), 1 \leq j \leq n,
$$

where $S_{o}$ is the entropy constant and defined as $S_{o}=(\ln (m))^{-1}, n$ is the number of sub-parameters and $m$ is the number of alternatives.

\section{Calculation of Degree of Divergence}

$$
D_{j}=1-S_{j}
$$

where $D$ is the degree of divergence.

\section{Sub-parameter weight calculation}

The weight of $j^{\text {th }}$ sub-parameter, $u_{j}$, is defined as

$$
u_{j}=D_{j} / \sum_{j=1}^{n} D_{j} 1 \leq j \leq n
$$


Here $\sum u_{j}=1$.

The measure of utility computation

$$
A_{i}=\sum_{j=1}^{n} u_{j}\left(Y_{j}^{*}-Y_{i j}\right) /\left(Y_{j}^{*}-Y_{j}^{-}\right)
$$

where $Y^{*}=\operatorname{MIN}_{j} ; Y^{-}=\operatorname{MAXY}_{j}$ and $A$ is utility measure

The measure of Regret Computation

The regret measure is obtained by

$$
B_{i}=\max \left\{u_{j}\left(Y_{j}^{*}-Y_{i j}\right) /\left(Y_{j}^{*}-Y_{j}^{-}\right)\right\}
$$

Generation of Ranking Indices of Main parameters

$$
K_{t}=\theta\left[\frac{A_{j}-A^{*}}{A^{*}-A^{-}}\right]+(1-\theta)\left[\frac{B_{j}-B^{*}}{B^{*}-B^{-}}\right] \text {where } 1 \leq t \leq g
$$

$K$ denotes the ranking index of alternative with respect to the main parameter.

$\theta$ is strategic weight representing maximal group utility, and $1-\theta$ is the weight of each regret measure.

$$
\begin{aligned}
& A^{*}=M I N A_{i} ; A^{-}=M_{i X A_{i}} \\
& B^{*}=M_{i}^{i} B_{i} ; B^{-}=M A A_{i}^{i} B_{i}
\end{aligned}
$$

Determination of Ranking Indices Matrices

The Ranking Indices Matrix with $m$ alternatives and $g$ columns is represented as.

$$
X=\left[\begin{array}{llll}
C_{1}+K_{1} & C_{2}+K_{2} & \cdots & C_{g}+K_{g}
\end{array}\right]
$$

where $C_{t}$ is partitioned columnar sub-matrices of $X$ initialized with value zero and $1 \leq t \leq g$.

Standard Deviation Computation

$$
\sigma_{j}=\sqrt{\frac{\sum\left(X_{i}-\bar{X}\right)^{2}}{n-1}}
$$

where $\bar{X}$ and $\sigma$ represents mean and standard deviation, respectively.

Calculation of main parameter weights

The weight of $j^{\text {th }}$ main parameter is calculated by.

$$
v_{j}=\sigma_{j} / \sum_{l=1}^{g} \sigma_{l}
$$

where $1 \leq j \leq g$ and $\sum v_{j}=1$.

Computation of weighted normalized decision matrix

The weighted normalized decision matrix is calculated by

$$
E_{i j}=P_{i j} v_{j}
$$

where $1 \leq i \leq m$ and $1 \leq j \leq g$.

Calculation of Positive Ideal solution

The positive ideal solution (most preferable alternative) is obtained by 


$$
\begin{aligned}
H^{*} & =\left\{\left(\max E_{i j} / j \in J\right),\left(\min E_{i j} / j \in J\right), 1 \leq i \leq m\right\} \\
& =\left\{e_{1}^{*}, e_{2}^{*}, \ldots, e_{g}^{*}\right\}
\end{aligned}
$$

\section{Calculation of Negative Ideal Solution}

The negative ideal solution (least preferable alternative) is obtained by

$$
\begin{aligned}
H^{-} & =\left\{\left(\min E_{i j} / j \in J\right),\left(\max E_{i j} / j \in J\right), 1 \leq i \leq m\right\} \\
& =\left\{e_{1}^{-}, e_{2}^{-}, \cdots, e_{g}^{-}\right\}
\end{aligned}
$$

\section{Determination of Separation Measure}

The separation distance of each alternative from the positive ideal solution is determined by

$$
Z_{i}^{*}=\sqrt{\sum_{j=1}^{g}\left(E_{i j}-e_{j}^{*}\right)^{2}} \text { where } 1 \leq i \leq m
$$

The separation distance of each alternative from the negative ideal solution is determined by

$$
Z_{i-}^{-}=\sqrt{\sum_{j=1}^{g}\left(E_{i j}-e_{j}^{-}\right)^{2}} \text { where } 1 \leq i \leq m
$$

\section{Computation of Final Assessment Values}

The final assessment values of the given alternatives can be obtained by

$$
F A_{i}=\frac{Z_{i}^{*}}{Z_{i}^{*}+Z_{i}^{-}}
$$

where $1 \leq i \leq m$ and $0 \leq F A_{i} \leq 1$.

The proposed system model is applied to agriculture dataset for ranking the sustainable sugar cane farms in terms of yield. The sugarcane farm dataset is obtained from arbitrarily identified villages located east of Eastern Ghats in Tamil Nadu, India. Primarily, 27 parameters have been identified for sustainable farming based on the recommendations made by agricultural experts. The 27 parameters have been grouped into seven main parameters, each having its own sub-parameters, as mentioned in Table 2 with notations used in this work. The associative significance of various sub-parameters for the respective main parameter occupies a vital part of the decision-making process. In this model, distinct approaches are utilized for computing the sub-parameters and main parameter's weights.

Table 2. Main parameters, sub-parameters, and their notations.

\begin{tabular}{cc}
\hline Main Parameters & Sub-Parameters \\
\hline Soil(MP1) & $\mathrm{EC}(\mathrm{s} 1), \mathrm{PH}(\mathrm{s} 2), \mathrm{N}(\mathrm{s} 3), \mathrm{P}(\mathrm{s} 4), \mathrm{K}(\mathrm{s} 5), \mathrm{Zn}(\mathrm{s} 6), \mathrm{Cu}(\mathrm{s} 7), \mathrm{Fe}(\mathrm{s} 8), \mathrm{Mn}(\mathrm{s} 9), \mathrm{Lime}$ status(s10), Texture(s11) \\
Water(MP2) & $\mathrm{EC}(\mathrm{wt} 1), \mathrm{PH}(\mathrm{wt} 2)$ \\
Season(MP3) & No sub-parameter \\
Input(MP4) & Nitrogen(i1), Urea(i2), P2O5(i3), SSP(i4), K2O(i5), MOP(i6) \\
Support(MP5) & Distance to Agri extension centres(st1), Distance to agri research centres(st2) \\
Facilities(MP6) & Distance to seed processing plants(ft1), Distance to markets(ft2), Distance to roads(ft3) \\
Risk(MP7) & Flood(r1), Winter rain(r2) \\
\hline
\end{tabular}

Generally, the source data gathered from the identified agricultural sites have to be segregated into sub-parameter matrices for every main parameter. It has to be noted that the source data gathered from farms have distinct units of measure. Therefore, for normalizing the source data, and also for ranking the identified sustainable sugarcane farms based on the main parameter, the ranking indices of all the main parameters are calculated. The VIKOR technique is utilized for determining the main 
parameters measures of ranking indices matrix. Hence, it can be observed that the source data available in the sub-parameter matrix is transformed into the main parameter measures of preference matrix.

Subsequently, the standard deviation technique is deployed for calculating the main parameters' associative weights. Furthermore, the main parameters' weights and its measure of ranking indices matrix are then employed to the TOPSIS approach for determining the assessment values of the identified sustainable sugarcane farms. Consequently, the farms are ranked by using the obtained assessment values.

The proposed ensemble VTOPES model is segregated into five different phases as follows:

\subsection{Phase 1}

Grouping the parameters into two different groups, namely the main parameters and sub-parameters (Table 2).

\subsection{Phase 2}

Computing the associative significance of sub-parameters for every corresponding main parameter. Shannon Entropy method is used for this purpose. In this objective weight assignment method, the entropy concept is used to measure the uncertainty occur in data. If the entropy value of a parameter is higher, then its corresponding weight will be smaller. Thus, the weights of sub-parameters are calculated using the entropy method and shown in Table 3.

Table 3. Weights of sub-parameters under each main parameter obtained using Shannon's Entropy method.

\begin{tabular}{|c|c|c|c|c|c|c|c|c|c|c|c|}
\hline MP1 & $\begin{array}{c}\mathbf{s 1} \\
0.0774\end{array}$ & $\begin{array}{c}\text { s2 } \\
0.0833\end{array}$ & $\begin{array}{c}\text { s3 } \\
0.0868\end{array}$ & $\begin{array}{c}\text { s4 } \\
0.1075\end{array}$ & $\begin{array}{c}\text { s5 } \\
0.1103\end{array}$ & $\begin{array}{c}\mathbf{s 6} \\
0.0857\end{array}$ & $\begin{array}{c}\mathbf{s 7} \\
0.0992\end{array}$ & $\begin{array}{c}\mathbf{s 8} \\
0.0931\end{array}$ & $\begin{array}{c}\text { s9 } \\
0.0737\end{array}$ & $\begin{array}{c}\mathbf{s 1 0} \\
0.0919\end{array}$ & $\begin{array}{c}\text { s11 } \\
0.0911\end{array}$ \\
\hline MP2 & $\begin{array}{c}\text { wt1 } \\
0.4980\end{array}$ & $\begin{array}{c}\text { wt2 } \\
0.5020\end{array}$ & & & & & & & & & \\
\hline MP3 & $\begin{array}{c}\text { i1 } \\
0.1808\end{array}$ & $\begin{array}{c}\text { i2 } \\
0.1309\end{array}$ & $\begin{array}{c}\text { i3 } \\
0.1744\end{array}$ & $\begin{array}{c}\text { i4 } \\
0.1833\end{array}$ & $\begin{array}{c}\text { i5 } \\
0.1672\end{array}$ & $\begin{array}{c}\mathbf{i 6} \\
0.1635\end{array}$ & & & & & \\
\hline MP4 & $\begin{array}{c}\text { st1 } \\
0.5033\end{array}$ & $\begin{array}{c}\text { st2 } \\
0.4967\end{array}$ & & & & & & & & & \\
\hline MP5 & $\begin{array}{c}\mathbf{f t 1} \\
0.3288\end{array}$ & $\begin{array}{c}\mathbf{f t} \mathbf{2} \\
0.3155\end{array}$ & $\begin{array}{c}\mathbf{f t 3} \\
0.3558\end{array}$ & & & & & & & & \\
\hline MP6 & $\begin{array}{c}\mathbf{r 1} \\
0.4418\end{array}$ & $\begin{array}{c}\mathbf{r 2} \\
0.5582\end{array}$ & & & & & & & & & \\
\hline
\end{tabular}

As the raw data obtained is in the form of sub-parameter matrix, it is desirable to combine the sub-parameter values into main parameter scores.

\subsection{Phase 3: Determining the Main Parameters' Ranking Indices of Identified Agricultural Farms}

Since the raw data may contain conflicting parameters, it is desirable to find compromise ranking solution. VIKOR is popular MCDM method used for finding compromise solution by considering maximum utility scores and minimum individual regret scores of the given alternatives. The weights of sub-parameters under each main parameter (Table 3) and their corresponding sub-parameter matrix are considered for finding the main parameters' ranking indices of sustainable sugarcane farms. The compromise solution is obtained by comparing the closeness measure of the optimal alternative [16]. The utility scores, regret scores, and ranking indices obtained for soil main parameter are shown in Table 4 . Thus, the ranking indices of each main parameter is obtained to form the final ranking indices matrix, which is shown in Table 5. 
Table 4. Utility, regret, and ranking scores of soil main parameter calculated using the VIKOR method.

\begin{tabular}{cccc}
\hline Farms & Utility Scores & Regret Scores & Ranking Indices \\
\hline F1 & 0.6418 & 0.0932 & 0.6167 \\
F2 & 0.6333 & 0.0919 & 0.6640 \\
F3 & 0.7361 & 0.0937 & 0.4602 \\
F4 & 0.7020 & 0.0919 & 0.5607 \\
F5 & 0.6244 & 0.0919 & 0.6773 \\
F6 & 0.4593 & 0.1003 & 0.6960 \\
F7 & 0.4715 & 0.1003 & 0.6776 \\
F8 & 0.4476 & 0.0932 & 0.9084 \\
F9 & 0.5480 & 0.0919 & 0.7920 \\
F10 & 0.5761 & 0.0919 & 0.7498 \\
F11 & 0.7392 & 0.1075 & 0.0809 \\
F12 & 0.5149 & 0.1003 & 0.6125 \\
F13 & 0.6166 & 0.0937 & 0.6398 \\
F14 & 0.5082 & 0.0919 & 0.8518 \\
F15 & 0.6734 & 0.0919 & 0.6037 \\
F16 & 0.4723 & 0.1103 & 0.4056 \\
F17 & 0.4095 & 0.1003 & 0.7708 \\
F18 & 0.7425 & 0.0931 & 0.4674 \\
F19 & 0.6478 & 0.0920 & 0.6406 \\
F20 & 0.7030 & 0.1075 & 0.1354 \\
\hline
\end{tabular}

Table 5. Ranking indices matrix for the identified main parameters.

\begin{tabular}{ccccccc}
\hline MP1 & MP2 & MP3 & MP4 & MP5 & MP6 & MP7 \\
\hline 0.6167 & 0.7404 & 1.0000 & 0.6591 & 0.2145 & 0.2930 & 0.3064 \\
0.6640 & 0.5874 & 0.5000 & 0.6223 & 0.2692 & 0.0910 & 0.3064 \\
0.4602 & 0.5861 & 1.0000 & 0.6461 & 0.1531 & 0.0254 & 1.0000 \\
0.5607 & 0.7404 & 0.5000 & 0.6591 & 0.0912 & 0.1920 & 0.3064 \\
0.6773 & 0.6880 & 0.5000 & 1.0000 & 0.7951 & 0.7980 & 0.5957 \\
0.6960 & 0.4530 & 0.5000 & 0.7078 & 0.1462 & 0.0379 & 0.4021 \\
0.6776 & 0.8735 & 0.5000 & 0.6829 & 0.2145 & 0.2930 & 0.5957 \\
0.9084 & 0.9675 & 0.5000 & 0.6591 & 0.0779 & 0.0910 & 0.3064 \\
0.7920 & 0.4530 & 0.5000 & 0.7747 & 0.0000 & 0.0254 & 0.3064 \\
0.7498 & 0.4867 & 0.5000 & 0.7316 & 0.0912 & 0.1920 & 0.3064 \\
0.0809 & 0.0060 & 0.5000 & 0.7078 & 0.7951 & 0.7980 & 1.0000 \\
0.6125 & 0.7404 & 1.0000 & 0.0753 & 0.6790 & 0.6970 & 0.0000 \\
0.6398 & 0.4530 & 1.0000 & 0.6591 & 1.0000 & 1.0000 & 0.5957 \\
0.8518 & 0.8735 & 1.0000 & 0.5000 & 0.0574 & 0.0254 & 0.4021 \\
0.6037 & 0.9675 & 1.0000 & 0.6223 & 0.0912 & 0.1920 & 0.5957 \\
0.4056 & 0.4530 & 1.0000 & 0.8522 & 0.7951 & 0.7980 & 1.0000 \\
0.7708 & 0.4867 & 0.5000 & 0.7939 & 0.6790 & 0.6970 & 0.0000 \\
0.4674 & 0.0325 & 0.0000 & 0.7379 & 0.9281 & 1.0000 & 0.5957 \\
0.6406 & 0.7404 & 0.5000 & 0.8761 & 0.2145 & 0.2930 & 1.0000 \\
0.1354 & 0.9675 & 0.5000 & 0.7078 & 0.2692 & 0.0910 & 0.5957 \\
\hline
\end{tabular}

\subsection{Phase 4: Main Parameters' Weight Computation}

A simple weight computation method, namely the standard deviation (SD) method, is used in this model for the computation of main parameter weights and shown in Table 6.

Table 6. Weights of Main parameters obtained using the standard deviation (SD) method.

\begin{tabular}{ccccccc}
\hline MP1 & MP2 & MP3 & MP4 & MP5 & MP6 & MP7 \\
\hline 0.2096 & 0.2059 & 0.1584 & 0.1010 & 0.1246 & 0.1232 & 0.0773 \\
\hline
\end{tabular}




\subsection{Phase 5: Determining the Assessment Values of Identified Agricultural Farms}

The final assessment values need to be determined in order to evaluate and rank the identified 20 sustainable sugarcane farms. There are possibilities that real-world data may contain imprecise and incomplete information. TOPSIS is popular MCDM method used to handle such data and provide reliable decisions. The main parameter weights obtained in phase 4 (Table 6) and ranking indices matrix obtained in phase 3 (Table 5) are applied to TOPSIS initially to compute weighted normalized matrix shown in Table 7. It considers the positive ideal solution or most preferable alternatives and negative ideal solution or least preferable alternatives (Table 8 ) for the evaluation of alternatives (farms). Then it measures the separation distance of each alternative from a positive ideal solution and negative ideal solution shown in Table 9 . This distance measure is used to find the proximity measure or assessment values of alternatives (Table 9).

Table 7. Weighted normalized decision matrix.

\begin{tabular}{ccccccc}
\hline MP1 & MP2 & MP3 & MP4 & MP5 & MP6 & MP7 \\
\hline 0.0456 & 0.0509 & 0.0501 & 0.0211 & 0.0119 & 0.0157 & 0.0089 \\
0.0490 & 0.0403 & 0.0250 & 0.0199 & 0.0149 & 0.0049 & 0.0089 \\
0.0340 & 0.0403 & 0.0501 & 0.0207 & 0.0085 & 0.0014 & 0.0292 \\
0.0414 & 0.0509 & 0.0250 & 0.0211 & 0.0051 & 0.0103 & 0.0089 \\
0.0500 & 0.0473 & 0.0250 & 0.0320 & 0.0441 & 0.0428 & 0.0174 \\
0.0514 & 0.0311 & 0.0250 & 0.0227 & 0.0081 & 0.0020 & 0.0117 \\
0.0501 & 0.0600 & 0.0250 & 0.0219 & 0.0119 & 0.0157 & 0.0174 \\
0.0671 & 0.0665 & 0.0250 & 0.0211 & 0.0043 & 0.0049 & 0.0089 \\
0.0585 & 0.0311 & 0.0250 & 0.0248 & 0.0000 & 0.0014 & 0.0089 \\
0.0554 & 0.0334 & 0.0250 & 0.0234 & 0.0051 & 0.0103 & 0.0089 \\
0.0060 & 0.0004 & 0.0250 & 0.0227 & 0.0441 & 0.0428 & 0.0292 \\
0.0452 & 0.0509 & 0.0501 & 0.0024 & 0.0377 & 0.0374 & 0.0000 \\
0.0473 & 0.0311 & 0.0501 & 0.0211 & 0.0555 & 0.0536 & 0.0174 \\
0.0629 & 0.0600 & 0.0501 & 0.0160 & 0.0032 & 0.0014 & 0.0117 \\
0.0446 & 0.0665 & 0.0501 & 0.0199 & 0.0051 & 0.0103 & 0.0174 \\
0.0300 & 0.0311 & 0.0501 & 0.0273 & 0.0441 & 0.0428 & 0.0292 \\
0.0569 & 0.0334 & 0.0250 & 0.0254 & 0.0377 & 0.0374 & 0.0000 \\
0.0345 & 0.0022 & 0.0000 & 0.0236 & 0.0515 & 0.0536 & 0.0174 \\
0.0473 & 0.0509 & 0.0250 & 0.0280 & 0.0119 & 0.0157 & 0.0292 \\
0.0100 & 0.0665 & 0.0250 & 0.0227 & 0.0149 & 0.0049 & 0.0174 \\
\hline
\end{tabular}

Table 8. Positive ideal solution and negative ideal solution.

\begin{tabular}{lcccccc}
\hline \multicolumn{7}{c}{ Most Preferable Alternatives/Positive Ideal Solution $\mathbf{H}^{*}$} \\
\hline 0.0671 & 0.0665 & 0.0501 & 0.0320 & 0.0555 & 0.0536 & 0.0292 \\
\hline \multicolumn{7}{c}{ Least preferable alternatives/negative ideal solution H- } \\
\hline 0.0060 & 0.0004 & 0.0000 & 0.0024 & 0.0000 & 0.0014 & 0.0000 \\
\hline
\end{tabular}


Table 9. Separation measures and final assessment values obtained using TOPSIS method.

\begin{tabular}{ccc}
\hline $\begin{array}{c}\text { Separation Measures from } \\
\text { Positive Ideal Solution }\end{array}$ & $\begin{array}{c}\text { Separation Measures from } \\
\text { Negative Ideal Solution }\end{array}$ & $\begin{array}{c}\text { Final Assessment } \\
\text { Values }\end{array}$ \\
\hline 0.0689 & 0.0864 & 0.5566 \\
0.0814 & 0.0686 & 0.4573 \\
0.0842 & 0.0786 & 0.4826 \\
0.0830 & 0.0705 & 0.4592 \\
0.0411 & 0.0996 & 0.7078 \\
0.0888 & 0.0652 & 0.4232 \\
0.0687 & 0.0849 & 0.5527 \\
0.0795 & 0.0963 & 0.5478 \\
0.0932 & 0.0701 & 0.4292 \\
0.0847 & 0.0692 & 0.4497 \\
0.0969 & 0.0746 & 0.4350 \\
0.0559 & 0.0973 & 0.6351 \\
0.0436 & 0.1100 & 0.7161 \\
0.0788 & 0.0987 & 0.5560 \\
0.0730 & 0.0959 & 0.5680 \\
0.0540 & 0.0973 & 0.6430 \\
0.0586 & 0.0876 & 0.5992 \\
0.0903 & 0.0836 & 0.4808 \\
0.0691 & 0.0826 & 0.5447 \\
0.0923 & 0.0772 & 0.4553 \\
\hline
\end{tabular}

\section{Results and Discussions}

The ranking results obtained using the assessment values calculated using VTOPES model is shown in Table 10. Also, these ranking outcomes obtained from the proposed system model are compared with the results of widespread MCDM techniques such as the grey relational analysis (GRA) and simple additive weight (SAW) approaches. Further, the previous five years mean yield/hectare data gathered from the sustainable sugarcane farms are utilized for validating these ranking outcomes.

Table 10. Validation results of VTOPES model compared with the results of the grey relational analysis (GRA) and simple additive weight (SAW) methods.

\begin{tabular}{ccccccc}
\hline S1 No. & $\begin{array}{c}\text { Sugarcane } \\
\text { Farms }\end{array}$ & $\begin{array}{c}\text { Average Yield Data } \\
\text { in Tonnes }\end{array}$ & $\begin{array}{c}\text { Yield } \\
\text { Ranks }\end{array}$ & $\begin{array}{c}\text { VTOPES } \\
\text { Ranks }\end{array}$ & $\begin{array}{c}\text { GRA } \\
\text { Ranks }\end{array}$ & $\begin{array}{c}\text { SAW } \\
\text { Ranks }\end{array}$ \\
\hline 1 & F13 & 9.8 & 1 & 1 & 1 & 1 \\
2 & F5 & 9.2 & 2 & 2 & 2 & 2 \\
3 & F16 & 8.4 & 3 & 3 & 3 & 3 \\
4 & F12 & 8.1 & 4 & 4 & 4 & 4 \\
5 & F17 & 7.9 & 5 & 5 & 5 & 7 \\
6 & F15 & 7.7 & 6 & 6 & 6 & 5 \\
7 & F1 & 7.5 & 7 & 7 & 9 & 10 \\
8 & F14 & 7.4 & 8 & 8 & 8 & 6 \\
9 & F7 & 7 & 9 & 11 & 7 & 8 \\
10 & F8 & 6.5 & 10 & 9 & 10 & 11 \\
11 & F19 & 6.3 & 11 & 10 & 11 & 9 \\
12 & F3 & 6 & 12 & 12 & 12 & 13 \\
13 & F18 & 5.8 & 13 & 13 & 13 & 12 \\
14 & F4 & 5.6 & 14 & 14 & 16 & 16 \\
15 & F2 & 5.3 & 15 & 15 & 15 & 18 \\
16 & F20 & 5 & 16 & 16 & 18 & 15 \\
17 & F10 & 4.7 & 17 & 17 & 17 & 17 \\
18 & F11 & 4.3 & 18 & 18 & 14 & 14 \\
19 & F9 & 4.2 & 19 & 19 & 20 & 19 \\
20 & F6 & 3.4 & 20 & 20 & 19 & 20 \\
\hline
\end{tabular}


The results thus obtained from VTOPES model, the GRA and SAW are compared with the ranking pattern acquired from the sustainable average yield data and represented in graphical format (Figure 1). In this graph, F1, F2, F3, etc., denote the identified agriculture farms as given in Table 10. Further, it can be noticed that the ranking patterns obtained from the average yield are in the form of a straight line. However, the ranking results of the VTOPES model shows minor deviations from the straight line. Besides, the GRA and SAW ranks depict significant deviations from the straight line in comparison with the VTOPES ranks.

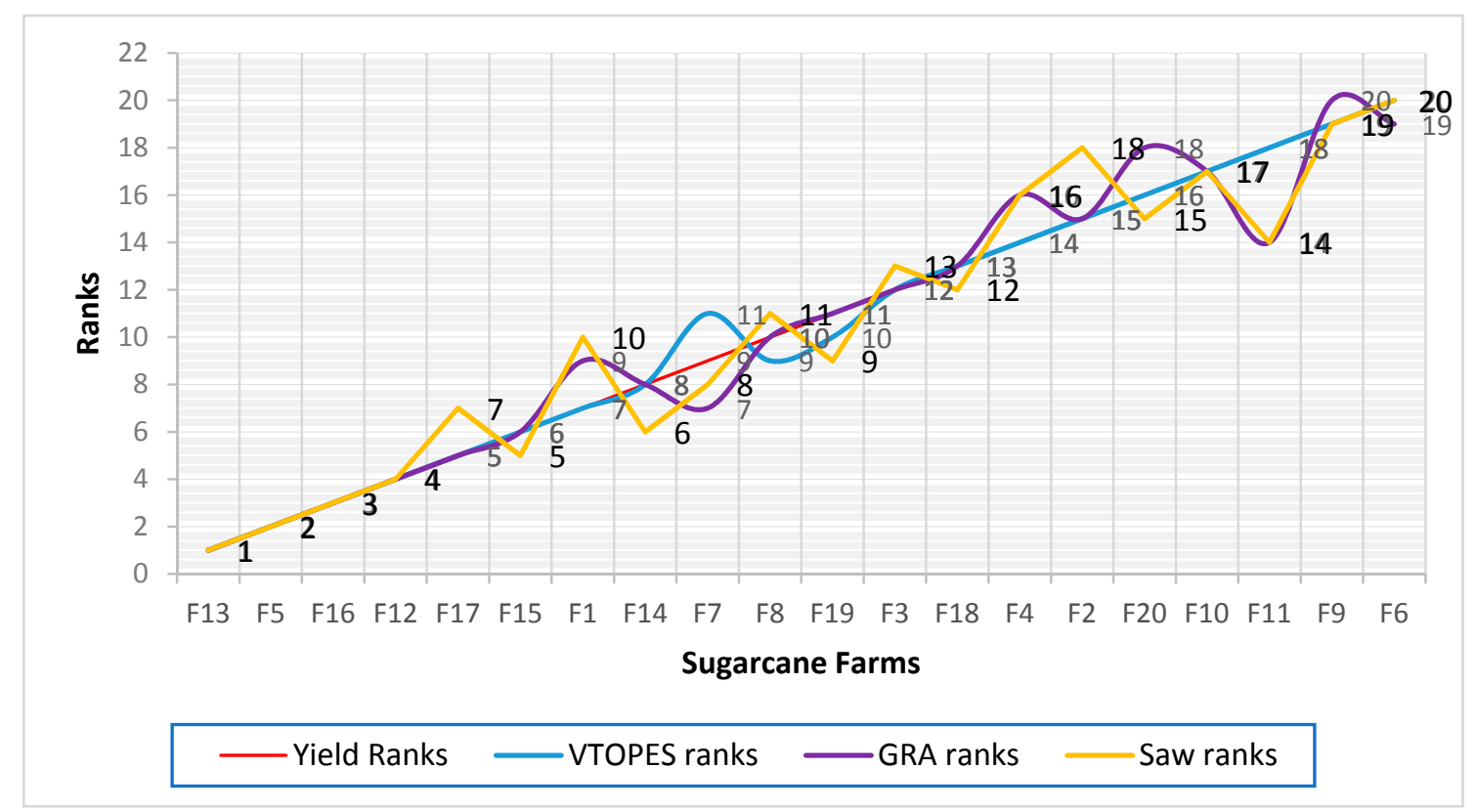

Figure 1. Graphical representation of ranking patterns obtained from average yield, VTOPES, GRA, and SAW.

Moreover, Spearman's rank correlation coefficient method is employed to test the significance of correlation among the ranks obtained from the developed model and the yield data. The value $\rho$ calculated for the developed model VTOPES model is 0.995 , GRA is 0.975 , and SAW is 0.961 . The critical value $\rho$ for the datasets with 20 trials with $\alpha$ value 0.01 is 0.544 . Therefore, the null hypothesis is rejected because the $\rho$ value acquired from the Spearman's rank correlation method is higher than the critical value $\rho$. Thus, the correlation between the ranking pattern acquired using the developed VTOPES model and the ranks obtained from the yield data is considered to be significant with $99 \%$ confidence level.

The VTOPES model correctly ranked 17 farms out of 20 agricultural farms, thus obtaining $85 \%$ of accuracy (Table 10). Whereas predictive mathematical model [6] accurately predicted 16 farms out of 20 farms and obtained $80 \%$ of accuracy. With respect to the time, as a predictive mathematical model integrates three weight calculation methods, two MCDM methods, it took more time to obtain decision results when compared to the proposed VTOPES model. Hence, the developed VTOPES model proves to produce accurate results for the given sustainable sugarcane farms, and it can be further applied to solve any MCDM problems where multiple parameters are considered.

\section{Conclusions}

This research presents an ensemble VTOPES system model for ranking and prediction of the best alternative among the given set of alternatives. VTOPES model comprises of methods for computation of significance scores of parameters and techniques for generation of ranking indices. In this work, the sugarcane farm dataset is applied for evaluating the performance of the VTOPES model for predicting the best sustainable sugarcane farm in terms of yield. The ranking patterns obtained from the VTOPES 
model are compared with the ranks acquired from the past five years sustainable average yield data, and the Spearman's rank correlation coefficient method is utilized for testing the significance of the correlation among the ranks. Further, the correlation between the VTOPES ranks and yield ranks are proved to be significant with $99 \%$ confidence level. Therefore, the proposed VTOPES model provides precise and sustainable results for the experimental dataset, and it can also be utilized for resolving any intricate real-world decision problems where multiple parameters are involved. Thus, the VTOPES model can be applied to obtain better results for sustainable development practices.

Author Contributions: This research specifies below the individual contributions. "Conceptualization, N D. and D.R.V. and; Data curation, K.S. and S.K.N; Formal analysis, N D. and S.K.N; Funding acquisition, C.-Y.C.; Investigation, D.R.V.; Methodology, K.S. and S.K.N; Project administration, K.S.; Resources, C.-Y.C.; Software A.K.B.; Supervision, A.K.B., K.S. and, C.-Y.C.; Validation, D.R.V. and K.S.; Visualization, N D. and D.R.V.; Writing review \& editing, N D. and K.S.

Funding: This research was partially funded by "Intelligent Recognition Industry Service Research Center" from The Featured Areas Research Center Program within the framework of the Higher Education Sprout Project by the Ministry of Education (MOE) in Taiwan. Grant number: N/A. And the APC was funded by the aforementioned Project.

Acknowledgments: Part of this work was financially supported by the "Intelligent Recognition Industry Service Research Center" from The Featured Areas Research Center Program within the framework of the Higher Education Sprout Project by the Ministry of Education (MOE) in Taiwan.

Conflicts of Interest: The authors declare no conflict of Interest.

\section{References}

1. Elavarasan, D.; Vincent, D.R.; Sharma, V.; Zomaya, A.Y.; Srinivasan, K. Forecasting yield by integrating agrarian factors and machine learning models: A survey. Comput. Electron. Agric. 2018, 155, 257-282. [CrossRef]

2. India Population (Live). Available online: http://www.worldometers.info/world-population/indiapopulation/ (accessed on 15 May 2019).

3. India GDP from Agriculture. Available online: https://tradingeconomics.com/india/gdp-from-agriculture (accessed on 17 May 2019).

4. Deepa, N.; Ganesan, K. Hybrid Rough Fuzzy Soft classifier based Multi-Class classification model for Agriculture crop selection. Soft Comput. 2018. [CrossRef]

5. Deepa, N.; Ganesan, K. Multi-class classification using hybrid soft decision model for agriculture crop selection. Neural Comput. Appl. 2018, 30, 1025-1038. [CrossRef]

6. Deepa, N.; Ganesan, K.; Sethuramasamyraja, B. Predictive mathematical model for solving multi-criteria decision-making problems. Neural Comput. Appl. 2018, 1-14. [CrossRef]

7. Deepa, N.; Ganesan, K. Decision-making tool for crop selection for agriculture development. Neural Comput. Appl. 2017, 31, No 4. 1215-1225. [CrossRef]

8. Deepa, N.; Ganesan, K. Mahalanobis Taguchi system based criteria selection tool for agriculture crops. Sädhanā 2016, 41, 1407-1414.

9. Qureshi, M.R.N.; Singh, R.K.; Hasan, M.A. Decision support model to select crop pattern for sustainable agricultural practices using fuzzy MCDM. Environ. Dev. Sustain. 2018, 20, 641-659. [CrossRef]

10. Cobuloglu, H.I.; Büyüktahtakın, İ.E. A stochastic multi-criteria decision analysis for sustainable biomass crop selection. Expert Syst. Appl. 2015, 42, 6065-6074. [CrossRef]

11. Wang, B.; Song, J.; Ren, J.; Li, K.; Duan, H.; Wang, X.E. Selecting sustainable energy conversion technologies for agricultural residues: A fuzzy AHP-VIKOR based prioritization from life cycle perspective. Resour. Conserv. Recycl. 2019, 142, 78-87. [CrossRef]

12. Golfam, P.; Ashofteh, P.S.; Loáiciga, H.A. Evaluation of the VIKOR and FOWA Multi-Criteria Decision Making Methods for Climate-Change Adaptation of Agricultural Water Supply. Water Resour. Manag. 2019, 33, 2867-2884. [CrossRef]

13. Chauhan, A.; Kaur, H.; Yadav, S.; Jakhar, S.K. A hybrid model for investigating and selecting a sustainable supply chain for agri-produce in India. Ann. Oper. Res. 2019, 1-22. [CrossRef] 
14. Hwang, C.L.; Yoon, K. Multiple Attribute Decision Making: Methods and Applications; Springer-Verlag: New York, NY, USA, 1981.

15. Roszkowska, E. Multi-criteria decision making models by applying the TOPSIS method to crisp and interval data. Mult. Criteria Decis. Making/Univ. Econ. Katow. 2011, 6, 200-230.

16. Opricovic, S.; Tzeng, G.H. Compromise solution by MCDM methods: A comparative analysis of VIKOR and TOPSIS. Eur. J. Oper. Res. 2004, 156, 445-455. [CrossRef]

17. Yazdani, M.; Graeml, F.R. VIKOR and its applications: A state-of-the-art survey. Int. J. Strateg. Decis. Sci. 2014, 5, 56-83. [CrossRef]

18. Julong, D. Introduction to grey system theory. J. Grey Syst. 1989, 1, 1-24.

19. Wang, T.K.; Zhang, Q.; Chong, H.Y.; Wang, X. Integrated supplier selection framework in a resilient construction supply chain: An approach via analytic hierarchy process (AHP) and grey relational analysis (GRA). Sustainability 2017, 9, 289. [CrossRef]

20. MacCrimmon, K.R. Decisionmaking Among Multiple-Attribute Alternatives: A Survey and Consolidated Approach (No. RM-4823-ARPA); Rand Corporation: Santa Monica, CA, USA, 1968.

21. Kaliszewski, I.; Podkopaev, D. Simple additive weighting-A metamodel for multiple criteria decision analysis methods. Expert Syst. Appl. 2016, 54, 155-161. [CrossRef]

22. Sasikumar, P.; Vimal, K.E.K. Evaluation and Selection of Green Suppliers Using Fuzzy VIKOR and Fuzzy TOPSIS. In Emerging Applications in Supply Chains for Sustainable Business Development; IGI Global: Hershey, PA, USA, 2019; pp. 202-218.

23. Ture, H.; Dogan, S.; Kocak, D. Assessing Euro 2020 Strategy Using Multi-criteria Decision Making Methods: VIKOR and TOPSIS. Soc. Indic. Res. 2019, 142, 645-665. [CrossRef]

24. Saaty, T.L. Decision making-The analytic hierarchy and network processes (AHP/ANP). J. Syst. Sci. Syst. Eng. 2004, 13, 1-35. [CrossRef]

25. Büyüközkan, G.; Göçer, F.; Karabulut, Y. A new group decision making approach with IF AHP and IF VIKOR for selecting hazardous waste carriers. Measurement 2019, 134, 66-82. [CrossRef]

26. Roy, B. The outranking approach and the foundations of ELECTRE methods. In Readings in Multiple Criteria Decision Aid; Springer: Berlin/Heidelberg, Germany, 1990; pp. 155-183.

27. Cali, S.; Balaman, Ş.Y. A novel outranking based multi criteria group decision making methodology integrating ELECTRE and VIKOR under intuitionistic fuzzy environment. Expert Syst. Appl. 2019, 119, 36-50. [CrossRef]

28. Chou, Y.C.; Yen, H.Y.; Dang, V.T.; Sun, C.C. Assessing the Human Resource in Science and Technology for Asian Countries: Application of Fuzzy AHP and Fuzzy TOPSIS. Symmetry 2019, 11, 251. [CrossRef]

29. Chang, C.Y.; Chen, S.J.; Tsai, M.F. Application of support-vector-machine-based method for feature selection and classification of thyroid nodules in ultrasound images. Pattern Recognit. 2010, 43, 3494-3506. [CrossRef]

30. Shannon, C.E. The Mathematical Theory of Communication; Shannon, C.E., Weaver, W., Eds.; University of Illinois Press: Chicago, IL, USA, 1998; pp. 29-125.

31. Singh, R.K.; Benyoucef, L. A consensus based group decision making methodology for strategic selection problems of supply chain coordination. Eng. Appl. Artif. Intell. 2013, 26, 122-134. [CrossRef]

32. Saaty, T.L. Analytic heirarchy process. In Wiley statsRef: Statistics Reference Online; John Wiley Sons Ltd.: Hoboken, NJ, USA, 2014.

33. Mert Kantar, Y. Estimating Variances in Weighted Least-Squares Estimation of Distributional Parameters. Math. Comput. Appl. 2016, 21, 7. [CrossRef]

34. Dalkey, N.; Helmer, O. An experimental application of the Delphi method to the use of experts. Manag. Sci. 1963, 9, 458-467. [CrossRef]

35. Khorramshahgol, R.; Moustakis, V.S. Delphic hierarchy process (DHP): A methodology for priority setting derived from the Delphi method and analytical hierarchy process. Eur. J. Oper. Res. 1988, 37, 347-354. [CrossRef]

(C) 2019 by the authors. Licensee MDPI, Basel, Switzerland. This article is an open access article distributed under the terms and conditions of the Creative Commons Attribution (CC BY) license (http://creativecommons.org/licenses/by/4.0/). 